\title{
The genus Hyalomma Koch, 1844. X. Redescription of all parasitic stages of $H$. (Euhyalomma) scupense Schulze, 1919 (= H. detritum Schulze) (Acari: Ixodidae) and notes on its biology
}

\author{
Dmitry A. Apanaskevich ${ }^{1}$, Natalia A. Filippova ${ }^{2}$ and Ivan G. Horak ${ }^{3}$ \\ ${ }^{1}$ United States National Tick Collection, the James H. Oliver, Jr. Institute of Arthropodology and Parasitology, Georgia Southern \\ University, Statesboro, Georgia 30460-8056, USA; \\ ${ }^{2}$ Zoological Institute, Russian Academy of Sciences, Saint Petersburg 199034, Russia; \\ ${ }^{3}$ Department of Veterinary Tropical Diseases, Faculty of Veterinary Science, University of Pretoria, Onderstepoort, \\ 0110, South Africa
}

\begin{abstract}
Taxonomic uncertainty as to the identities of Hyalomma (Euhyalomma) scupense Schulze, 1919 and Hyalomma detritum Schulze, 1919 has existed for nearly 85 years. The chief criterion used to consider these taxa as separate species has been an ecological feature, namely that $H$. scupense is a one-host tick while $H$. detritum is a two-host species. Morphologically they are identical. To date no comprehensive taxonomic study has been done on all parasitic stages of the two species. Here the decision to grant priority status to $H$. scupense and to synonymise $H$. detritum with $H$. scupense is defended. The adults and immature stages of $H$. scupense are illustrated and redescribed. The morphological characteristics that separate the males, females, nymphs and larvae from those of other Hyalomma species are discussed for each developmental stage. Data on hosts, geographic distribution and disease relationships are provided.
\end{abstract}

Keywords: Hyalomma (Euhyalomma) scupense, systematics, male, female, nymph, larva, distribution, hosts

Hyalomma (Euhyalomma) scupense Schulze, 1919 (imprint 1918) was originally described as an independent species (Schulze 1919a). In the same year, but in a later issue of the same journal, Schulze (1919b) described a similar species that he called Hyalomma detritum Schulze, 1919. Since then both species have been considered independent, but differentiation between them was practically impossible because it was based on a few variable characters. The main criterion for distinguishing between the species was of an ecological nature, namely that $H$. scupense is a one-host species while $H$. detritum is a two-host species. Delpy (1947) considered H. scupense a variant of $H$. detritum, namely $H$. detritum var. scupense. This, however, is in conflict with the rules of the International Code of Zoological Nomenclature (ICZN, 1999), in that H. scupense should have priority. Pomerantzev (1950) and Hoogstraal (1956) had doubted the validity of $H$. scupense, and assumed that it may be a winter one-host race of the more widely distributed $H$. detritum, but neither of them effected any nomenclatural changes. Feider (1965) repeated the attempts of Delpy to discover consensus between the morphological similarity of the two species and differences in their ecological traits. In contrast to Delpy, however, he considered $H$. detritum a subspecies of $H$. scupense, namely $H$. scupense detritum. According to the ICZN this was nomenclaturally correct, but the name was not generally accepted. Camicas et al. (1998) resurrected the nomenclaturally incorrect standpoint of Delpy (1947) and designated H. scupense a subspecies of $H$. detritum. After examining the syntypes of $H$. scupense and the holotype of $H$. detritum, Filippova (2003) concluded that $H$. detritum should be regarded as a junior subjective synonym of $H$. scupense and as a junior objective synonym of Hyalomma marginatum Koch, 1844. Guglielmone et al. (2009) accepted the latter point of view. The current situation is thus confused both as to the names and their status: traditionally some workers consider both $H$. scupense and $H$. detritum as full species, others believe $H$. scupense to be a subspecies of $H$. detritum, and a third group accepts $H$. detritum as a junior synonym of $H$. scupense. In addition the taxonomic confusion surrounding these ticks has been compounded with the description of numerous species and subspecies closely resembling $H$. scupense by Schulze and his coworkers (Schulze 1930). 
Descriptions and illustrations of the adults as $\mathrm{H}$. scupense and $H$. detritum are available in several publications, but we consider the most useful of these to be found in Pomerantzev (1950) and Hoogstraal (1956). The nymph and larva are schematically illustrated and described as H. mauritanicum in Senevet $(1924,1928)$, as $H$. scupense and H. detritum in Ogandzhanyan (1953) and Dzhaparidze (1960), and as H. scupense in Feider (1965).

After examining the type material of both ticks as well as numerous ticks that had been identified as either $H$. scupense or $H$. detritum we conclude that $H$. detritum should be treated not only as a junior subjective synonym of $H$. scupense but also as its objective synonym.

The aim of this study is to redescribe and illustrate all the parasitic stages of the hereby authenticated species, H. scupense. These descriptions should assist parasitologists and epidemiologists in their studies on the biology and medico-veterinary importance of this widely distributed species.

\section{MATERIALS AND METHODS}

A total of approximately 4500 males, 2500 females, 650 nymphs, and 400 larvae of $H$. scupense, originating from Afghanistan, Algeria, Armenia, Azerbaijan, China, Egypt, France, Georgia, Greece, India, Iran, Iraq, Italy, Jordan, Kazakhstan, Kyrgyzstan, Lebanon, Macedonia, Moldova, Morocco, Oman, Pakistan, Romania, Russia, Sudan, Syria, Tajikistan, Tunisia, Turkey, Turkmenistan, Ukraine and Uzbekistan, were examined during the present study. The largest samples of specimens examined in our study came from Iraq and Kazakhstan. Both fieldcollected and laboratory-reared specimens were scrutinised. The lectotype and paralectotypes of $H$. scupense were also examined by Apanaskevich and Filippova. The specimens we looked at are housed in the United States National Tick Collection (USNTC) (the James H. Oliver, Jr. Institute of Arthropodology and Parasitology, Georgia Southern University, Statesboro, USA), the Zoological Institute, Russian Academy of Sciences (ZIN RAS) (Saint Petersburg, Russia), the Natural History Museum of Berlin (NHMB) (Germany), the Field Museum of Natural History (FMNH) (Chicago, USA), the Gertrud Theiler Tick Museum at the Onderstepoort Veterinary Institute (OVI) (Onderstepoort, South Africa) and in the personal tick collection of Dr. J.B. Walker (South Africa). A detailed list of the material studied can be found at http://personal.georgiasouthern.edu/ dapanask/data on Hyalomma scupense.pdf.

The immature stages and the more delicate structures of the adults were mounted on glass slides and examined under a light microscope, and the macrostructures of males and females under a stereoscopic microscope. The spiracular plates of the nymph were studied by means of a scanning electron microscope. Measurements for the male conscutum and female scutum are given in millimetres $(\mathrm{mm})$, and those for the various features of the immature stages in micrometres $(\mu \mathrm{m})$. The measurements are arranged as follows: minimum - maximum (mean \pm standard deviation, $\mathrm{n}=$ number of specimens measured). Their schematic layout is to be found in Apanaskevich (2003), and Apanaskevich and Horak (2006). All illustrations were done by Apanaskevich.

\section{RESULTS}

Hyalomma (Euhyalomma) scupense Schulze, 1919

Figs. 1-7

Type specimens. The original description was based on male and female (unquantified) from Skopje, Macedonia, ex cattle, December 1917 (Schulze 1919a). The type specimens (Lectotype, 1 male, Üsküb, Rind, Dezember 1917, ZMB 8494; Paralectotypes, 1 male and 1 female, the label the same as for lectotype) are deposited in the NHMB. The lectotype has been designated by Filippova (2003). Additional specimens from Schulze's collection of $H$. scupense, with the same or similar label data as for the type specimens, are deposited in the USNTC (1 female, Ueskub, 12.17, RML 49671; 21 males, 13 females, 14 nymphs, Üsküb, Rind, Dez. 17, RML 49675; 11 males, 30 females, 27 nymphs, Üsküb, Rind, RML 49670) and ZIN RAS (2 males, 2 females, Üsküb, Rind, 5049).

Synonyms (Camicas et al. 1998 with corrections):

Hyalomma detritum Schulze, 1919; Hyalomma detritum albipictum Schulze, 1919; Hyalomma mauritanicum Senevet, 1922; Hyalomma mauritanicum annulatum Senevet, 1922; Hyalomma detritum annulatum Senevet, 1922 sensu Schulze, 1923; Hyalomma detritum detritum Schulze, 1919 sensu Schulze, 1927; Hyalomma aegyptium ferozedini Sharif, 1928; Hyalomma detritum damascenium Schulze et Schlottke, 1930; Hyalomma detritum dardanicum Schulze et Schlottke, 1930; Hyalomma volgense Schulze et Schlottke, 1930; Hyalomma uralense Schulze et Schlottke, 1930; Hyalomma detritum rubrum Schulze et Olenev in Schulze, 1930; Hyalomma detritum mauritanicum Senevet, 1922 sensu Schulze, 1930; Hyalomma detritum perstrigatum Schulze, 1930; Hyalomma verae Olenev, 1931; Hyalomma steineri Schulze et Gossel in Schulze, 1936; Hyalomma steineri steineri Schulze et Gossel in Schulze, 1936; Hyalomma dardanicum Schulze et Schlottke, 1930 sensu Kaplan, 1946; Hyalomma dardonicum Kaplan, 1946 (lapsus); Hyalomma detritum var. scupense Schulze, 1919 sensu Delpy, 1947; Hyalomma detritum scupense Schulze, 1919 sensu Delpy, 1949; Hyalomma steineri enigkianum Schulze, 1950; Hyalomma scupense detritum Schulze, 1919 sensu Feider, 1965; Hyalomma scupense scupense Schulze, 1919 sensu Feider, 1965.

The type specimens of $H$. detritum (1 male; Holotypus; Golodnaya Steppe, Transkaspien; Heymons und Samter leg.; ZMB 11449 and 1 male, 1 female; Syntypen; Golodnaya Steppe, Transkaspien; Heymons und Samter leg.; ZMB 11448) are deposited in the NHMB and have been examined by Apanaskevich and Filippova. We consider this name a junior synonym of $H$. scupense, but not of H. marginatum (Filippova 2003).

The type specimen of $H$. detritum albipictum (1 female; Syntypen; Tsingtau, Eggebrecht leg.; ZMB 16735) 

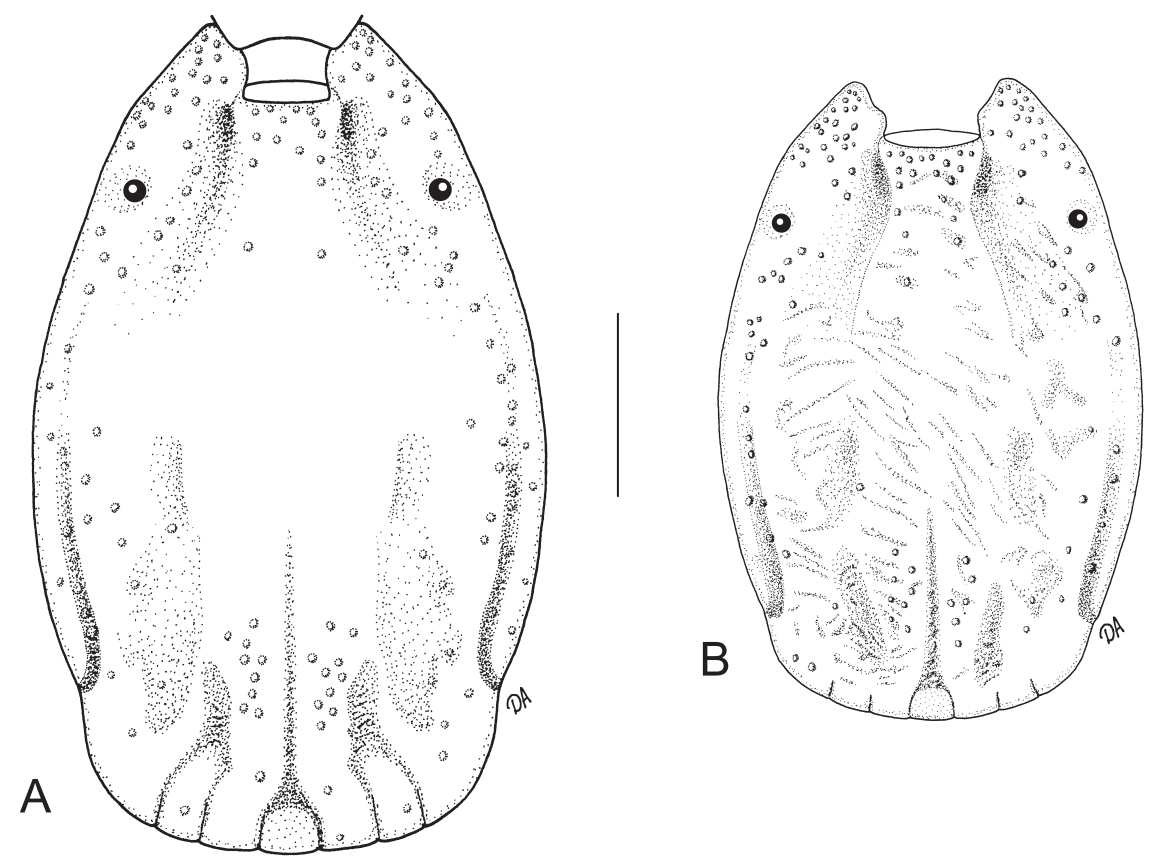

Fig. 1. Hyalomma scupense, male, conscutum (A, B - showing variations). All setae are omitted. Scale bar $=1 \mathrm{~mm}$.

is deposited in the NHMB and has been examined by Apanaskevich. Additional specimens of Schulze's collections of $H$. detritum albipictum are in the ZIN RAS (2 males, 2 females; Tsingtau, Rind; 2329) and in Schulze's collection at the USNTC (20 females; Tsingtau, Eggebrecht, 1909; USNTC 49528 and 71 males, 1 female; Tsingtau, Eggebrecht, 1909; USNTC 49536). We confirm the synonymy.

The type specimen of $H$. detritum perstrigatum (1 female; Holotypus; Peking; ZMB 11450) is deposited in the NHMB and has been examined by Apanaskevich. We confirm the synonymy.

The type specimens of $H$. verae (1 female; Lectotype; lower Etzin-gol river, near lake Sogo-nor, Antelope ( $\mathrm{Ga}$ zella) subgutturosa, 24.III-28.IV.1926, N.N. Przhevalskiy leg.; И2970; 4 females; label the same as for lectotype; И2970a) are deposited in the ZIN RAS and have been examined by Apanaskevich and Filippova. Additional specimens of Olenev's collection of $H$. verae are in the ZIN RAS ( 2 males, 2 females; lower Etzin-gol river, near lake Sogo-nor, Antilope (Gazella) subgutturosa, 1926, Przhevalskiy; 5 females; lower Etzin-gol river, near lake Sogo-nor, 24.III-28.IV.1926, Przhevalskiy; 469). We confirm the synonymy.

We have discovered 2 males of $H$. detritum dardanicum (Prilep, Mazedonien, Rind, 27.VII.1917, D. Behu leg.; USNTC 49529) in the collection of Schulze in the USNTC. Prilep (Macedonia) is the type locality for H. detritum dardanicum (Schulze and Schlottke 1930). It is possible that these specimens originate from the original type series. Its synonymy has been confirmed by Apanaskevich.
We have found 2 males of $H$. steineri (Uzak, Anatolien, Rind, Steiner leg.; USNTC 49519) in the collection of Schulze in the USNTC. Uşak (Turkey) is the type locality for H. steineri (Schulze 1936). It is possible that these specimens originate from the original type series. Its synonymy has been confirmed by Apanaskevich.

Hyalomma steineri codinai Schulze et Gossel, 1936 and Hyalomma transcaucasicum Olenev, 1934 have been deleted from the list of synonyms for H. scupense and $H$. detritum created by Camicas et al. (1998), because a previous study of the type specimens revealed that they are junior synonyms of Hyalomma marginatum Koch, 1844 (Apanaskevich and Horak 2008).

Delpy (1949) placed $H$. sharifi amongst the synonyms of H. detritum and Camicas et al. (1998) agreed. At the same time Camicas et al. (1998) proposed H. aegyptium forma typica Sharif, 1928 as a junior synonym of H. anatolicum anatolicum Koch, 1844. However, Kratz (1940) stated that Schulze and Schlottke's (1930) description of $H$. sharifi was based on a description and illustration of $H$. aegyptium by Sharif (1928). We consequently regard $H$. sharifi as a questionable junior synonym of $H$. anatolicum, but not of $H$. scupense (Camicas et al. 1998).

\section{Description}

\section{Male}

Figs. 1A, B, 2A-I, 3A

Conscutum (Fig. 1A, B): length 3.26-5.12 (4.14 \pm 0.43 , $\mathrm{n}=100)$, width $1.98-3.01(2.58 \pm 0.25, \mathrm{n}=100)$, ratio length:width 1.37-1.81 (1.61 $\pm 0.08, \mathrm{n}=100)$; red-brown 


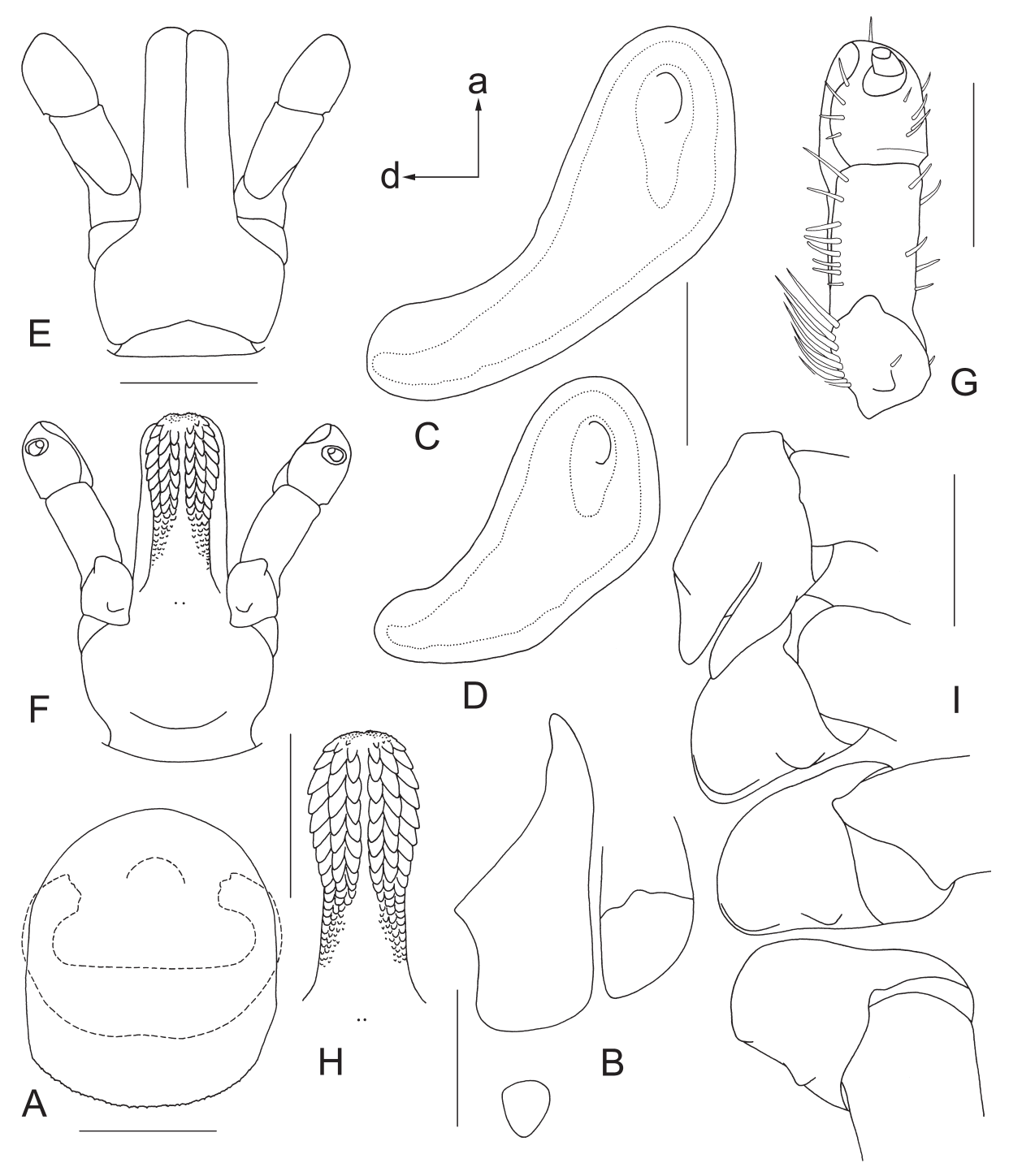

Fig. 2. Hyalomma scupense, male. A - genital structures; $\mathbf{B}$ - anal plates; C, D - spiracular plate (a - anterior, d - dorsal); $\mathbf{E}$ - gnathosoma dorsally; $\mathbf{F}$ - gnathosoma ventrally; $\mathbf{G}$ - palp ventrally; H - hypostome; I - coxae. All setae are omitted except drawing G in which only setae of palpal segment IV are omitted. Scale bars: A $=200 \mu \mathrm{m} ; \mathrm{B}, \mathrm{D}, \mathrm{E}, \mathrm{H}=500 \mu \mathrm{m} ; \mathrm{C}, \mathrm{F}, \mathrm{G}=400 \mu \mathrm{m}$.

in colour; pale marbling absent; broadly oval in shape; widest at mid-length; slight narrowing in region of spiracular plates; cervical and lateral grooves shallow, fairly short, up to $1 / 3$ length of conscutum; marginal grooves short or moderate in length, furrow-like, extending to mid-length of conscutum; posteromedian groove furrowlike and reaching parma; paramedian grooves clearly defined; caudal field well defined; large punctations sparsely distributed, mainly anteriorly in the central field, and in the lateral and caudal fields; a patchwork of rugosities sometimes alters the smoothness of the surface (Fig. 1B); dome-shaped parma normally present; 4 distinct festoons. Genital structures (Fig. 2A) as illustrated. Anal shields (Fig. 2B): 3 pairs; adanal plates long, broad, lateral margin slightly convex at its two extremities and straight between them, anteromedian margin concave, median projection broad, distinct, posteromedian margin straight, posterior margin mildly convex; subanal plates variable both in size and shape, usually moderately-sized, with rounded angles and longitudinally aligned. Ventral sclerotized plaques absent on median, but present on paramedian festoons. Spiracular plate (Fig. 2C, D): dorsal prolongation long and clearly distinct from body of plate; perforated portion of prolongation relatively broad, straight, tapering to its curved apex. Circumspiracular setae sparse.

Basis capituli (Fig. 2E, F): without lateral projections; dorsal posterior margin concave; cornua moderate. Palpi (Fig. 2G): segment I with more than 5 ventromedian setae. Hypostome (Fig. 2H): club-shaped; denticulate portion slightly longer than denticle-free portion (small scale-like projections posterior to last large denticle are not considered denticles). 
Coxae (Fig. 2I): posteromedian and posterolateral spurs of coxa I long, subequal in length or posterolateral spur longer than posteromedian spur, close together, tapering to apices; coxae II-IV each with distinct, triangular, posterolateral spur with rounded apex; coxae II and III each with slight, broadly arcuate, posteromedian spur; posteromedian spur on coxa IV distinct, triangular. Leg segments uniformly brown, or with ivory-coloured enamel stripe on their dorsal aspects (Fig. 3A).

\section{Female}

Figs. 3B, 4, 5A-H

Scutum (Fig. 4): length 1.82-2.56 (2.19 \pm 0.17 , $\mathrm{n}=100)$, width $1.73-2.40(2.08 \pm 0.14, \mathrm{n}=100)$, ratio length:width 0.96-1.15 (1.05 $\pm 0.04, \mathrm{n}=100)$; red-brown in colour; pale marbling absent; nearly as long as broad; posterolateral angles slight; cervical and lateral grooves shallow, extending to posterior margin of scutum; very sparse, deep, uniformly distributed large punctations on anterior $2 / 3$ of scutum; rugose patches sometimes alter the smoothness of the surface. Genital structures (Fig. 5A): genital aperture wide, deep, V-shaped; vestibular portion of vagina not bulging; preatrial fold of genital aperture bulging anteriorly and sloping posteriorly (Fig. 5B). Spiracular plates (Fig. 5C): perforated portion of dorsal prolongation relatively broad, curved, tapering to its apex. Circumspiracular setae sparse.

Basis capituli (Fig. 5D, E): dorsolateral projections short, only just visible ventrally; dorsal posterior margin slightly concave; dorsal cornua inconspicuous. Palpi (Fig. 5F): segment I with more than 5 ventromedian setae. Hypostome (Fig. 5G): club-shaped; denticulate portion slightly longer than denticle-free portion.

Coxae (Fig. 5H): posteromedian and posterolateral spurs of coxa I long, subequal in length or posterolateral spur longer than posteromedian spur, tapering to apices, close together; coxae II-IV each with distinct, broadly triangular posterolateral spur, with rounded apex; coxae II-IV each with modest, broadly arcuate, posteromedian spur. Colouration of legs similar to that of male (Fig. 3B).

\section{Nymph}

Figs. 6A-G

Scutum (Fig. 6A, B): length 572-954 (723 \pm 74 , $\mathrm{n}=133)$, width $612-895 \quad(724 \pm 62, \quad \mathrm{n}=137)$, ratio length:width $0.80-1.16(1.00 \pm 0.06, \mathrm{n}=132)$, distance between posterior margin of eyes and posterior margin of scutum 198-360 $(279 \pm 32, \mathrm{n}=135)$, ratio width:length of posterior portion of scutum 2.22-3.59 (2.60 \pm 0.24 , $\mathrm{n}=135$ ); posterior margin of scutum broadly rounded; posterolateral, marginal concavities on either side of scutal apex shallow to easily discernable. Setae of alloscutum (Fig. 6C): without denticles, gently tapering to rounded apex. Spiracular plates (Fig. 6D): circular; dorsal prolongation indistinct; submarginal and marginal rows of small perforations present only in dorsoposterior sector.

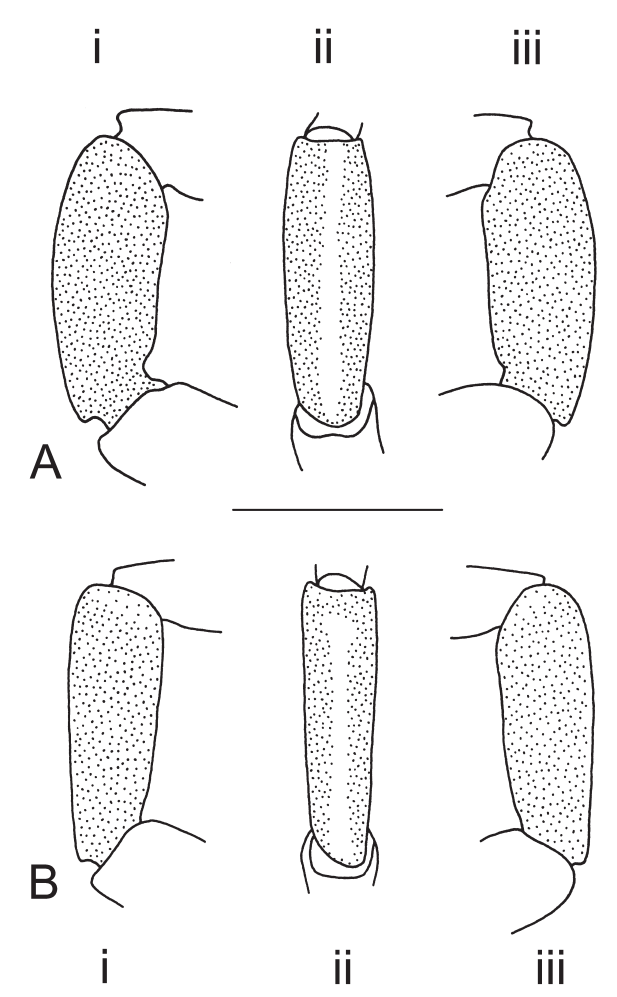

Fig. 3. Hyalomma scupense, genu IV. A - male: i - lateral view, ii - dorsal view, iii - medial view; B - female: $\mathrm{i}$ - lateral view, ii - dorsal view, iii - medial view. All setae are omitted. Scale bar $=1 \mathrm{~mm}$.

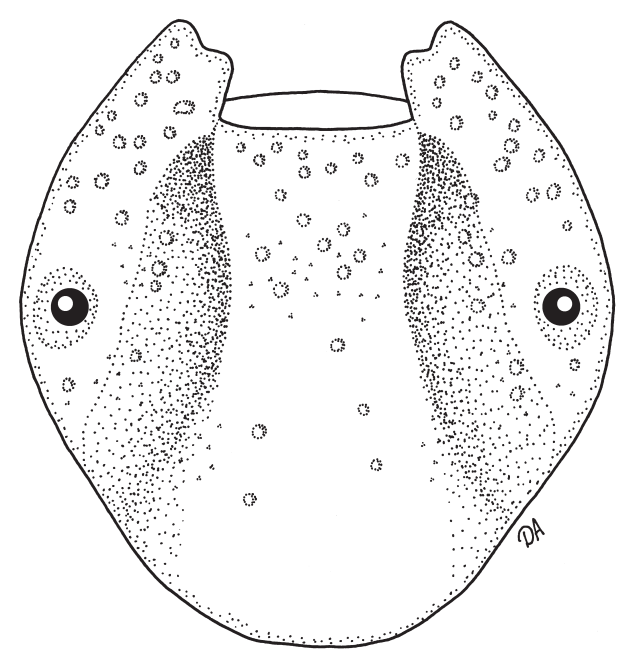

Fig. 4. Hyalomma scupense, female, scutum. All setae are omitted. Scale bar $=1 \mathrm{~mm}$.

Basis capituli (Fig. 6E, F): length 440-547 (491 \pm 27 , $\mathrm{n}=35)$; width $346-507 \quad(420 \pm 36, \quad \mathrm{n}=134)$, ratio length:width $1.08-1.38(1.26 \pm 0.06, \mathrm{n}=35)$. Palpi (segment II) (Fig. 6E, F): length 165-234 (198 $\pm 15, \mathrm{n}=136)$, 


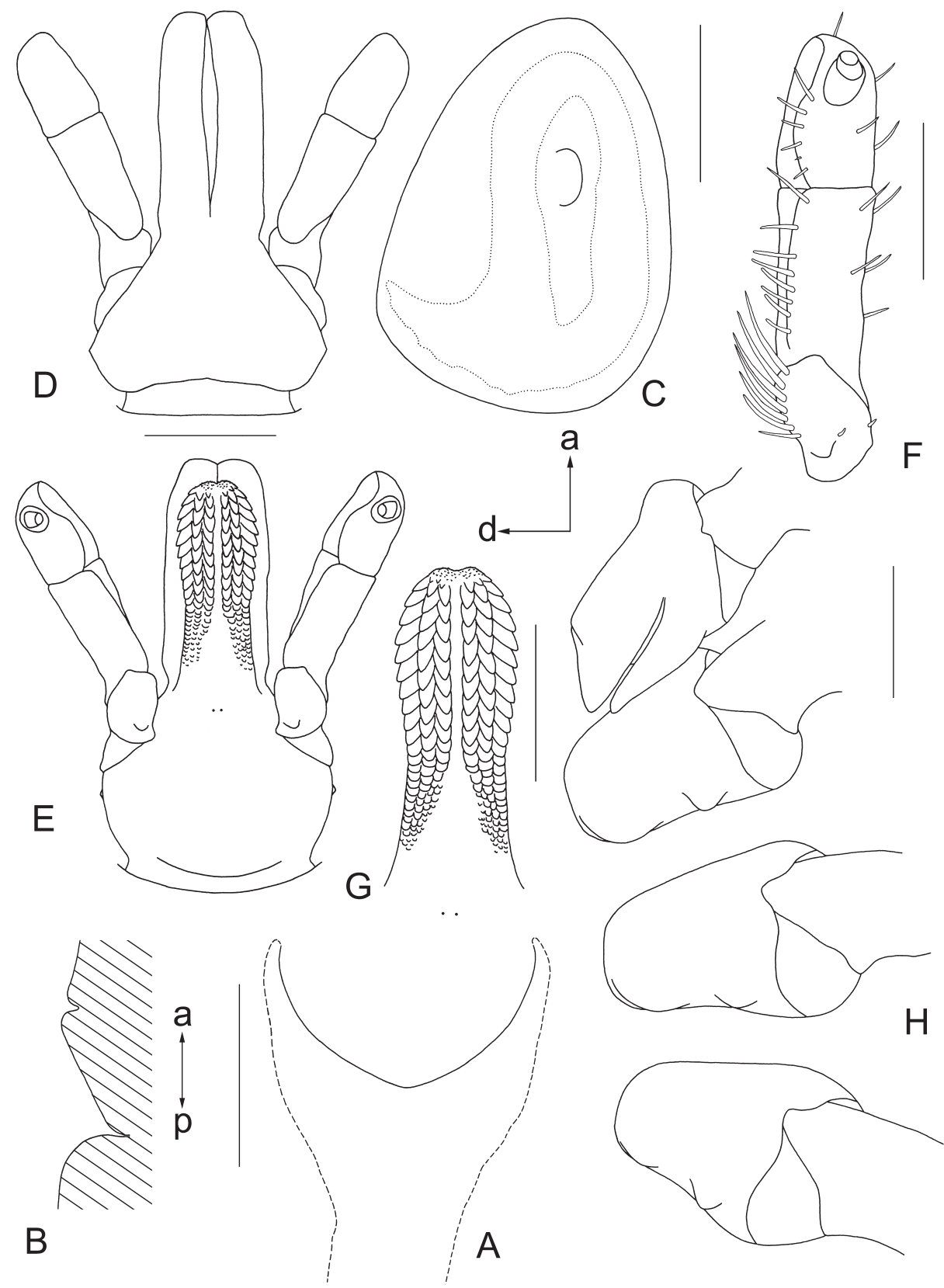

Fig. 5. Hyalomma scupense, female. A - genital structures; B - longitudinal section through preatrial fold of schematic genital aperture (a - anterior, $\mathrm{p}$ - posterior); $\mathbf{C}$ - spiracular plate (a - anterior, $\mathrm{d}$ - dorsal); D - gnathosoma dorsally; $\mathbf{E}$ - gnathosoma ventrally; $\mathbf{F}$ - palp ventrally; $\mathbf{G}$ - hypostome; $\mathbf{H}$ - coxae. All setae are omitted except drawing F in which only setae of palpal segment IV are omitted. Scale bars: $A=200 \mu \mathrm{m} ; \mathrm{C}, \mathrm{F}, \mathrm{G}=400 \mu \mathrm{m} ; \mathrm{E}, \mathrm{D}, \mathrm{H}=500 \mu \mathrm{m}$.

width $57-85(71 \pm 5, \mathrm{n}=136)$, ratio length:width 2.32 $3.18(2.78 \pm 0.17, \mathrm{n}=136)$; palpal segment II proximally broad, expanding slightly distally. Hypostome (Fig. 6F): length 240-325 (268 $\pm 21, \mathrm{n}=46)$, width 64-109 (84 \pm 9 , $\mathrm{n}=107)$, ratio length:width $2.77-4.57 \quad(3.25 \pm 0.31$, $\mathrm{n}=46$ ); median file with 7 or 8 large denticles; transition of denticulate portion to denticle-free portion abrupt; denticulate portion as long as denticle-free portion.

Coxae (Fig. 6G): coxa I with long, broad, subtriangular posterolateral spur and considerably shorter, subtriangu- lar posteromedian spur; coxae II-IV each with minute, fold-like spur, spurs conspicuously decreasing in size from coxae II to IV; coxal pore absent.

\section{Larva}

Figs. 7A-D

Scutum (Fig. 7A): length 264-325 $(298 \pm 15, \mathrm{n}=120)$, width 376-456 $(410 \pm 16, \mathrm{n}=136)$, ratio length:width $0.67-0.81(0.73 \pm 0.03, \mathrm{n}=120)$, distance from posterior margin of eyes to posterior margin of scutum 91-125 $(113 \pm 8, \mathrm{n}=120)$, ratio width:length of posterior portion 


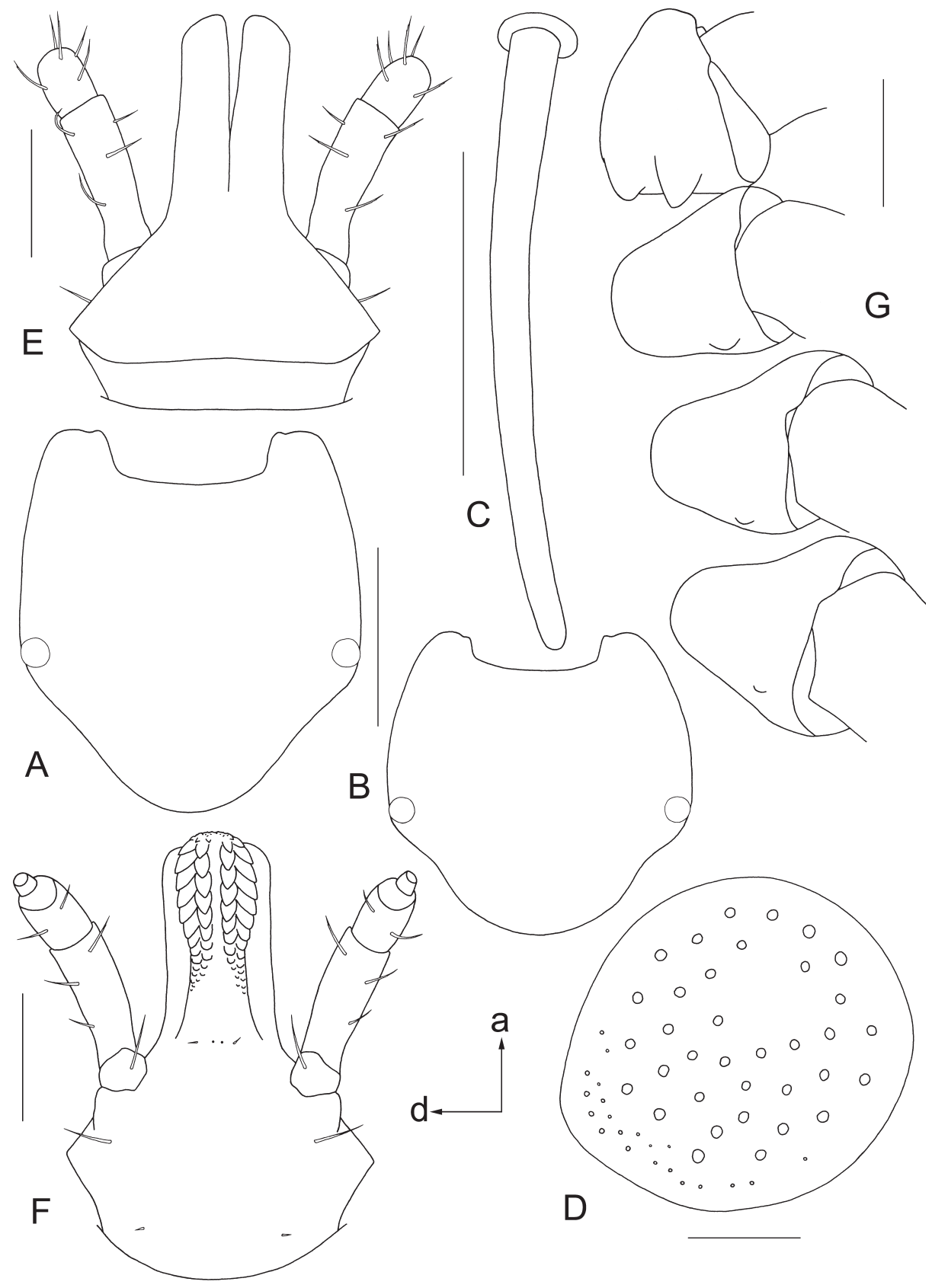

Fig. 6. Hyalomma scupense, nymph. A, B - scutum; C - seta of alloscutum; D - spiracular plate (a - anterior, d - dorsal); $\mathbf{E}$ - gnathosoma dorsally; $\mathbf{F}$ - gnathosoma ventrally; $\mathbf{G}$ - coxae. All setae are omitted except drawings $E$ and $F$ in which only setae of palpal segment IV are omitted. Scale bars: $A=400 \mu \mathrm{m} ; \mathrm{B}, \mathrm{C}=50 \mu \mathrm{m} ; \mathrm{D}-\mathrm{F}=200 \mu \mathrm{m}$.

$3.13-4.50(3.67 \pm 0.28, \mathrm{n}=120)$. Portion of scutum posterior to eyes equal to $1 / 2$ scutal length; posterior margin of scutum broadly rounded; posterolateral marginal concavities on either side of apex indistinct.

Basis capituli (Figs. 7B, C): 143-196 (163 \pm 11 , $\mathrm{n}=137)$; subhexagonal dorsally; subrectangular ventrally; apices of dorsolateral projections directed laterally; lateral projections only just visible ventrally. Palpi (segments II and III) (Fig. 7B, C): length 106-136 $(125 \pm 6, \mathrm{n}=143)$, width $36-48(43 \pm 2, \mathrm{n}=142)$, ratio length:width 2.55-3.31 (2.91 $\pm 0.18, \mathrm{n}=142)$. Нуроstome (Fig. 7C): length 104-129 (119 $\pm 7, \mathrm{n}=115)$, width 29-39 $(35 \pm 2, \mathrm{n}=123)$, ratio length:width 2.71-3.83 $(3.34 \pm 0.24, \mathrm{n}=101)$; median file with 5 large denticles; transition of denticulate portion to denticle-free portion abrupt; denticulate portion approximately $1 / 2$ hypostomal length.

Coxae (Figs. 7D): coxa I with very short, broad, subtriangular spur, with rounded apex; coxae II-III each with small, fold-like, indistinct spur. Genua I: length 126-168 


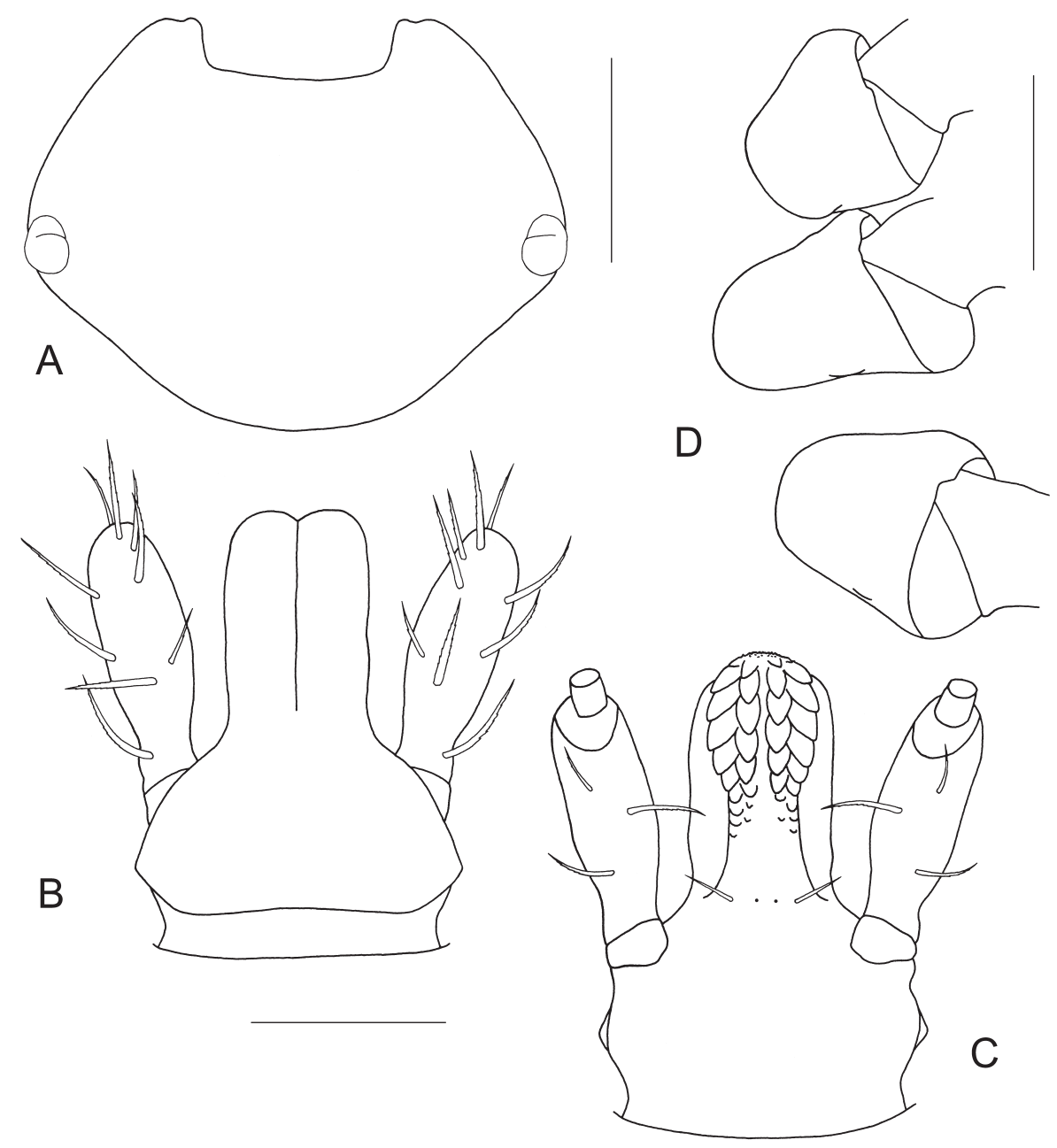

Fig. 7. Hyalomma scupense, larva. A - scutum; $\mathbf{B}$ - gnathosoma dorsally; $\mathbf{C}$ - gnathosoma ventrally; $\mathbf{D}$ - coxae. All setae are omitted except drawings B and C in which only setae of palpal segment IV are omitted. Scale bars: A = $150 \mu \mathrm{m} ; \mathrm{B}-\mathrm{D}=100 \mu \mathrm{m}$.

$(147 \pm 7, \mathrm{n}=142)$, width $42-53(49 \pm 3, \mathrm{n}=85)$, ratio length:width 2.63-3.33 $(2.97 \pm 0.16, \mathrm{n}=85)$.

\section{Variability}

Individual and geographic variability in the morphological appearance of $H$. scupense is very extensive as illustrated and described above. For example, specimens from the northern portion of its geographic range often display rugose patches on their conscutum (Fig. 1B) or scutum, a shorter and broader perforated portion of the dorsal prolongation of the spiracular plates (Fig. 2D), and absence of an ivory-coloured dorsal strip on leg segments.

\section{Interspecific morphological relationships}

A combination of the morphological characters of $H$. scupense makes this taxon different from any of the other Euhyalomma species.

The male of $H$. scupense only superficially resembles those of $H$. dromedarii Koch, 1844 and H. isaaci Sharif, 1928 by its deep furrow-like posteromedian groove that reaches the parma and the sparseness of large punctations on the conscutum. The male of $H$. scupense can easily be distinguished from that of $H$. dromedarii by its short and shallow cervical groves, and usually longer marginal groove, straighter adanal plates, absence of ivorycoloured enamelled circles around distal margin of leg segments (in $H$. dromedarii: cervical grooves very long and deep, marginal grooves short, adanal plates distinctly curved medially, distal margin of leg segments encircled by ivory-coloured enamelling); from that of $H$. isaaci by its shorter marginal grooves, its well-developed parma, sparse circumspiracular setae, lack of ivory-coloured enamelled circles around distal margin of leg segments (in H. isaaci: marginal grooves very long, parma absent, circumspiracular setae moderately dense, ivory-coloured enamelled circles around distal margin of leg segments).

The female of $H$. scupense superficially resembles those of $H$. albiparmatum Schulze, 1919, H. nitidum Schulze, 1919, H. schulzei Olenev, 1931 and H. truncatum Koch, 1844 by its very broad and long genital aperture. The female of $H$. scupense differs from that of all these 
species by the broad V-shape of its genital aperture compared to the others' broadly U-shaped genital apertures with broadly arcuate or straight posterior margins. The female of $H$. scupense can additionally be distinguished from $H$. nitidum by the sloping preatrial fold of the genital aperture (in $H$. nitidum: bulging); from $H$. schulzei by its shallow cervical grooves, sparse large punctations on scutum and absence of ivory-coloured enamelling around distal margins of leg segments (in H. schulzei: cervical grooves very deep, moderately dense small punctations on scutum, and leg segments with ivory-coloured enamelling around their distal margins); from H. albiparmatum and $H$. truncatum by its lack of ivory-coloured enamelling around distal margins of leg segments but presence of dorsal ivory-coloured strip (in H. albiparmatum and H. truncatum: leg segments have ivory-coloured enamelling around their distal margins but no ivory-coloured dorsal strip).

The nymph of $H$. scupense can be distinguished from those of other Hyalomma species by its very short posteromedian spur on coxa I, very small fold-like spurs on coxae II-IV, round spiracular plates, lack of small perforations on spiracular plate except in its dorsoposterior sector, measurements and their ratios (see description).

The larva of H. scupense is similar to those of $H$. albiparmatum, H. franchinii Tonelli Rondelli, 1932, H. glabrum Delpy, 1949, H. isaaci, H. lusitanicum Koch, 1844, $H$. marginatum, $H$. nitidum, $H$. rufipes Koch, 1844, H. truncatum and H. turanicum Pomerantzev, 1946 in the ratio of the portion of the scutum posterior to the eyes, which is nearly $1 / 2$ of the total scutal length. The larva of $H$. scupense can be distinguished from those of $H$. glabrum, H. isaaci, H. marginatum, H. rufipes and H. turanicum by the 5 denticles in files on its hypostome and a denticulate portion that comprises $1 / 2$ the total hypostomal length (in the other species: 6-7 denticles per file and denticulate portion is $2 / 3$ of hypostomal length); from those of $H$. albiparmatum, $H$. lusitanicum, $H$. nitidum and $H$. truncatum by its very short rounded spur on coxa I and indistinct fold-like spurs on coxae II and III (in the other species the spur on coxa I is long, subtriangular, moderate to large and spurs on coxae II and III are moderate or large); from that of $H$. franchinii by the poorly defined lateral projections on the basis capituli and by its measurements and their ratios (in $H$. franchinii: lateral projections on basis capituli clearly defined; for measurements see Apanaskevich et al. 2008).

\section{Hosts}

Hyalomma scupense is a one- or two-host species (Pomerantzev 1950, Hoogstraal 1956). Both the adults and the immature stages use large and medium-sized ungulates as hosts. They have been collected mainly from domesticated species, namely cattle, camels, horses, donkeys, buffaloes, sheep, goats and pigs. Some collections have been made from wild ungulates, such as European roe, Capreolus capreolus (Linnaeus), red deer, Cervus elaphus Linnaeus, goitered gazelle, Gazella subgutturosa (Güldenstädt), argali, Ovis ammon (Linnaeus), wild boar, Sus scrofa Linnaeus and onager, Equus hemionus Pallas. Single records are known from domestic dogs, foxes, Vulpes sp., striped hyena, Hyaena hyaena (Linnaeus) and hares, Lepus sp. Humans are often attacked by the adults of this species (Pomerantzev 1950, Hoogstraal 1956, Berdyev 1980, our data).

\section{Geographic distribution}

Hyalomma scupense has one of the largest distribution ranges amongst the Hyalomma ticks, extending from Western Europe and North Africa to Eastern China. The geographic distribution of this species lies entirely within the Palaearctic zoogeographic region.

Europe: Albania, Bosnia and Herzegovina, Bulgaria, Croatia, France, Greece, Italy, Macedonia, Moldova, Montenegro, Romania, Russia (south of the European part and North Caucasus), Serbia, Spain and Ukraine; Asia: Afghanistan, Armenia, Azerbaijan, China, Georgia, India, Iran, Iraq, Israel, Jordan, Kazakhstan, Kyrgyzstan, Lebanon, Nepal, Oman, Pakistan, Syria, Tajikistan, Turkey, Turkmenistan and Uzbekistan; Africa: Algeria, Egypt, Libya, Morocco, Sudan and Tunisia (Hoogstraal 1956, Kolonin 1983, our data).

\section{Disease relationships}

Hyalomma scupense is an important vector of Theileria annulata, the causative organism of tropical theileriosis or Mediterranean coast fever in domestic cattle (Pipano and Shkap 2004). In most endemic regions the disease has a seasonal occurrence between June and September, which is related to the biology and ecology of its vectors (Flach and Ouhelli 1992, Bouattour et al. 1996). A single Hyalomma tick is capable of transmitting a fatal infection (Pipano et al. 1982). It is also a vector of Theileria equi, one of the causative organisms of equine piroplasmosis (De Waal and Van Heerden 2004). This tick is also a vector of Coxiella burnetii, the causative agent of Q-fever, and Crimean-Congo haemorrhagic fever virus (Hoogstraal 1956, 1979). It can also harbour the disease agents causing plague, tularaemia and brucellosis (Hoogstraal 1956).

Acknowledgements. We are most grateful to Drs. J. Dunlop (NHMB), D. Summers (FMNH), J.B. Walker (South Africa) and Ms H. Heyne (OVI) for making specimens available for our study. The contribution of N.A. Filippova to this manuscript is based upon long-term research supported by the Russian Foundation for Basic Research (06-04-48220a and 09-04-00738). The contribution of I.G. Horak has been partially funded by the National Research Foundation of South Africa; any opinions expressed herein are those of the author, and the NRF does not accept any liability in regard thereto. 


\section{REFERENCES}

Apanaskevich D.A. 2003: Differentiation of closely related species Hyalomma anatolicum and $H$. excavatum (Acari, Ixodidae) based on a study of all life cycle stages, throughout their entire geographical range. Parazitologiya 37: 259-280.

Apanaskevich D.A., Horak I.G. 2006: The genus Hyalomma Koch, 1844. I. Reinstatement of Hyalomma (Euhyalomma) glabrum Delpy, 1949 (Acari, Ixodidae) as a valid species with a redescription of the adults, the first description of its immature stages and notes on its biology. Onderstepoort J. Vet. Res. 73: $1-12$.

Apanaskevich D.A., Horak I.G. 2008: The genus Hyalomma Koch, 1844: V. Re-evaluation of the taxonomic rank of taxa comprising the H. (Euhyalomma) marginatum Koch complex of species (Acari: Ixodidae) with redescription of all parasitic stages and notes on biology. Int. J. Acarol. 34: 13-42.

Apanaskevich D.A., Santos-Silva M.M., Horak I.G. 2008: The genus Hyalomma Koch, 1844. IV. Redescription of all parasitic stages of $H$. (Euhyalomma) lusitanicum Koch, 1844 and the adults of $H$. (E.) franchinii Tonelli Rondelli, 1932 (Acari: Ixodidae) with a first description of its immature stages. Folia Parasitol. 55: 61-74.

Berdyev A. 1980: [Ecology of ixodid ticks of Turkmenistan and their role in epizootiology of natural focal diseases]. Ylym, Ashkhabad, 281 pp. (In Russian.)

Bouattour A., Darghouth M.A., Ben Miled L. 1996: Cattle infestation by Hyalomma ticks and prevalence of Theileria in H. detritum species in Tunisia. Vet. Parasitol. 65: 233-245.

Camicas J.L., Hervy J.P., Adam F., Morel P.C. 1998: The Ticks of the World (Acarida, Ixodida). Nomenclature, Described Stages, Hosts, Distribution. Orstom éditions, Paris, 233 pp.

Delpy L.P. 1947: Révision, par des voies expérimentales, du genre Hyalomma C.L., Koch 1884 (Acarina, Ixodoidea, Ixodidae). Note préliminaire. Ann. Parasitol. Hum. Comp. 21: 267-293.

Delpy L.P. 1949: Essai critique de synonymie du genre Hyalomma C.L. Koch 1844 depuis Linné, 1758. Ann. Parasitol. Hum. Comp. 24: 464-494.

De Waal D.T., Van Heerden J. 2004: Equine piroplasmosis. In: J.A.W. Coetzer and R.C. Tustin (Eds.), Infectious Diseases of Livestock. Oxford University Press Southern Africa, Cape Town, pp. 425-434.

Dzhaparidze N.I. 1960: [Ixodid ticks of Georgia]. Izd. Akad. Nauk Gruzinskoy SSR, Tbilisi, 295 pp. (In Russian.)

Feider Z. 1965: Fauna Republicii Populare Române. Arachnida, Vol. 5, fasc. 2. Acaromorpha, Suprafamilia Ixodoidea (Căpuşe). Editura Academiei Republicii Populare Române, Bucureşti, 404 pp.

Filippova N.A. 2003: Re-investigation of type series of Hyalomma scupense Schulze, 1918 and H. detritum Schulze, 1919 (Acari: Ixodidae) in connection with microevolutionary process within the genus. Parazitologiya 37: 455-461.

Flach E.J., Ouhelli H. 1992: The epidemiology of tropical theileriosis (Theileria annulata infection in cattle) in an endemic area of Morocco. Vet. Parasitol. 44: 51-65.

Guglielmone A.A., Robbins R.G., Apanaskevich D.A., Petney T.N., Estrada-Peña A., Horak I.G. 2009: Comments on

Received 17 December 2009 controversial tick (Acari: Ixodida) species names and species described or resurrected from 2003 to 2008. Exp. Appl. Acarol. 48: 311-327.

Hoogstraal H. 1956: African Ixodoidea. I. Ticks of the Sudan (with special reference to Equatoria province and with preliminary reviews of the genera Boophilus, Margaropus, and Hyalomma). Department of the Navy, Washington D.C., 1101 pp.

Hoogstraal H. 1979: The epidemiology of tick-borne CrimeanCongo hemorrhagic fever in Asia, Europe and Africa. J. Med. Entomol. 15: 307-417.

International Code of Zoological Nomenclature 1999. Fourth edition. http://www.iczn.org/iczn

Kolonin G.V. 1983: [World distribution of ixodid ticks. Genera Hyalomma, Aponomma, Amblyomma.] Izd. Nauka, Moscow, 120 pp. (In Russian).

Kratz W. 1940: Die Zeckengattung Hyalomma Koch. Z. Parasitenkd. 11: 510-562.

OGandzhanyan A.M. 1953: [Larvae and nymphs of ticks of the genus Hyalomma Koch of Armenian SSR.] Zool. Sb. Zool. Inst. Akad. Nauk Armyan. SSR 8: 149-167. (In Russian).

Pipano E., SAmish M., Krigel Y. 1982: Relative infectivity of Theileria annulata (Dschunkowsky and Luhs, 1904) stabilates derived from female and male Hyalomma excavatum (Koch, 1844) ticks. Vet. Parasitol. 10: 21-27.

Pipano E., Shkap V. 2004: Theileria annulata theileriosis. In: J.A.W. Coetzer and R.C. Tustin (Eds.), Infectious Diseases of Livestock. Oxford University Press Southern Africa, Cape Town, pp. 486-497.

Pomerantzev B.I. 1950: [Ixodid ticks (Ixodidae).] Fauna SSSR, Paukoobraznye, Vol. 4, No. 2. Izd. Akad. Nauk SSSR, Moscow, Leningrad, 224 pp. (In Russian.)

Schulze P. 1919a: Ein Beitrag zur Zeckenfauna Mazedoniens. Sitzungsber. Ges. Naturforsch. Freunde Berl. 1-2: 61-66.

Schulze P. 1919b: Bestimmungstabellen für das Zeckengenus Hyalomma Koch. Sitzungsber. Ges. Naturforsch. Freunde Berl. 5: 189-196.

Schulze P. 1930: Die Zeckengattung Hyalomma I. (H. aegyptium L., detritum P. Sch., volgense P. Sch. u. Schlottke, H. scupense P. Sch. und H. uralense P. Sch. u. Schlottke.). Z. Parasitenkd. 3: $22-48$.

Schulze P. 1936: Zwei neue Arten der Gattung Hyalomma und die morphologische Bedeutung der Analbeschilderung der Ixodiden. Zool. Anz. 114: 187-192.

Schulze P., Schlottke E. 1930: Bestimmungstabellen für das Zeckengenus Hyalomma Koch s. str. Sitzungsber. Abh. Naturforsch. Ges. Rostock 2: 32-46.

Senevet G. 1924: Description de la nymphe de Hyalomma mauritanicum Senevet 1922. Arch. Inst. Pasteur Algér. 2: 233-234.

Senevet G. 1928: Clé pour la détermination des larves d'Ixodidés trouvées sur les bovines en Algérie. Arch. Inst. Pasteur Algér. 6: 42-46.

SHARIF M. 1928: A revision of the Indian Ixodidae with special reference to the collection in the Indian Museum. Rec. Indian Mus. 30: 217-344.

Accepted 7 February 2010 